\title{
STUDIES ON ALCOHOL DIURESIS. II. THE EVALUATION OF ETHYL ALCOHOL AS AN INHIBITOR OF THE NEUROHYPOPHYSIS 1, 2
}

\author{
By CHARLES R. KLEEMAN, MILTON E. RUBINI,³ EZRA LAMDIN,‘ AND \\ FRANKLIN H. EPSTEIN \\ (From the Department of Internal Medicine, Yale University School of Medicine, \\ New Haven, Conn.)
}

(Submitted for publication September 7, 1954 ; accepted November 24, 1954)

In the normally hydrated semi-recumbent individual, alcohol causes a rise in urine flow that is characterized by an increase of free water clearance $\left(\mathrm{C}_{\mathrm{H}_{2} \mathrm{O}}\right)$ and a decreased excretion of sodium, potassium and chloride (1). The evidence to date strongly suggests that the rise of $\mathrm{CH}_{2} \mathrm{O}$ is caused by inhibition of the release of antidiuretic hormone.

The present study was undertaken to evaluate the effect of alcohol on the excretion of water and solutes in physiologic states in which alterations in the activity of antidiuretic hormone have been demonstrated or suggested. The following states were studied: 1) Minimal antidiuretic hormones $(\mathrm{ADH})$ activity produced by sustained positive loads of water; 2) Increased $\mathrm{ADH}$ activity produced by infusions of hypertonic sodium chloride solutions, a) during water diuresis with high urine flows (10 to $15 \mathrm{cc}$. per min.), and b) in subjects with low urine flows ( 1 to 2 cc. per min.) ; 3 ) Increased antidiuretic activity produced by venous congestion of the limbs.

\section{MATERIALS, METHODS AND RESULTS}

Subjects were normal males, aged 25 to 32 . No control of diet prior to the day of study was attempted. One to one and a half hours after a light breakfast the subjects voided and reclined in a semi-recumbent position. All studies were begun at 8:30 to 9:00 A.M.; diurnal variations in urinary flow and composition (2) were therefore presumably similar in all experiments. Alcohol was given as 120 cc. of 100 proof bourbon whisky imbibed over a 10-minute period. Techniques for collection of blood and urine and chemical methods have been described in the previous paper (1). In all studies insensible water loss was assumed to be approximately $50 \mathrm{cc}$. per hour. Changes in extracellular

1 Supported in part by a Grant from the U. S. Public Health Service.

2 Presented in abstract form at the meeting of the American Society for Clinical Investigation, Atlantic City, May 2-5, 1954.

3 Major, MC, USA.

4 Postdoctorate Research Fellow of the U. S. Public Health Service. space were calculated approximately from changes in the chloride space (3), assuming an initial extracellular volume of 20 per cent of body weight. Changes in plasma volume were calculated from changes in hemoglobin and hematocrit (1). Urine flow was divided into two fractions :

Osmolar clearance $\left(\mathrm{C}_{\mathrm{osm}}\right)$

$$
\begin{aligned}
& =\frac{\text { milliosmols per kilo of urine }}{\text { milliosmols per kilo of plasma }} \\
& \qquad \text { urine flow (cc. per min.) }
\end{aligned}
$$

Free water clearance $\left(\mathrm{C}_{\mathrm{H}_{2} \mathrm{O}}\right)=$ urine flow $-\mathrm{C}_{\mathrm{oam}}$

Group I. Effect of alcohol during water diuresis (Table $I$, Figure 1C)

A positive water balance was induced in two semirecumbent subjects by drinking one liter of water, and was maintained by infusing 4 per cent fructose solution intravenously and administering supplemental water by mouth. The accuracy of this technique was checked by weighing the subject at the beginning and the end of each experiment. Fructose solution was chosen because of its minimal effect on the total hexose in the blood. By limiting the rate of infusion to $8 \mathrm{cc}$. per minute or less, no reducing substances could be detected in the urine by qualitative test with Benedict's solution. After a maximal steady urine flow had been maintained for at least two 30-minute periods, alcohol was imbibed. Urine was collected at 15 to 30 -minute intervals during the next three hours.

Under these circumstances, alcohol did not induce a further increase in urine flow or $\mathrm{CH}_{2} \mathrm{O}$ (Figure 1C). If large positive loads of water (1000 cc.) completely inhibit ADH release ("physiologic diabetes insipidus"), this result would be expected.5 The rates of excretion

5 The statement that maximum water diuresis is associated with complete inhibition of $\mathrm{ADH}$ release or socalled "physiologic diabetes insipidus" probably is true for the recumbent and semi-recumbent positions only. In unpublished experiments the authors have demonstrated that when a positive water load of $1000 \mathrm{cc}$. is maintained, the maximum urinary flow and free water clearance $\left(\mathrm{C}_{2} \mathrm{O}\right)$ attained in the standing or $45^{\circ}$ position were further increased by lying down. This suggests a continual "tonic" release of ADH in the upright positions in spite of the sustained water load or nonhormonal factors blocking the maximum rise in urinary flow. 


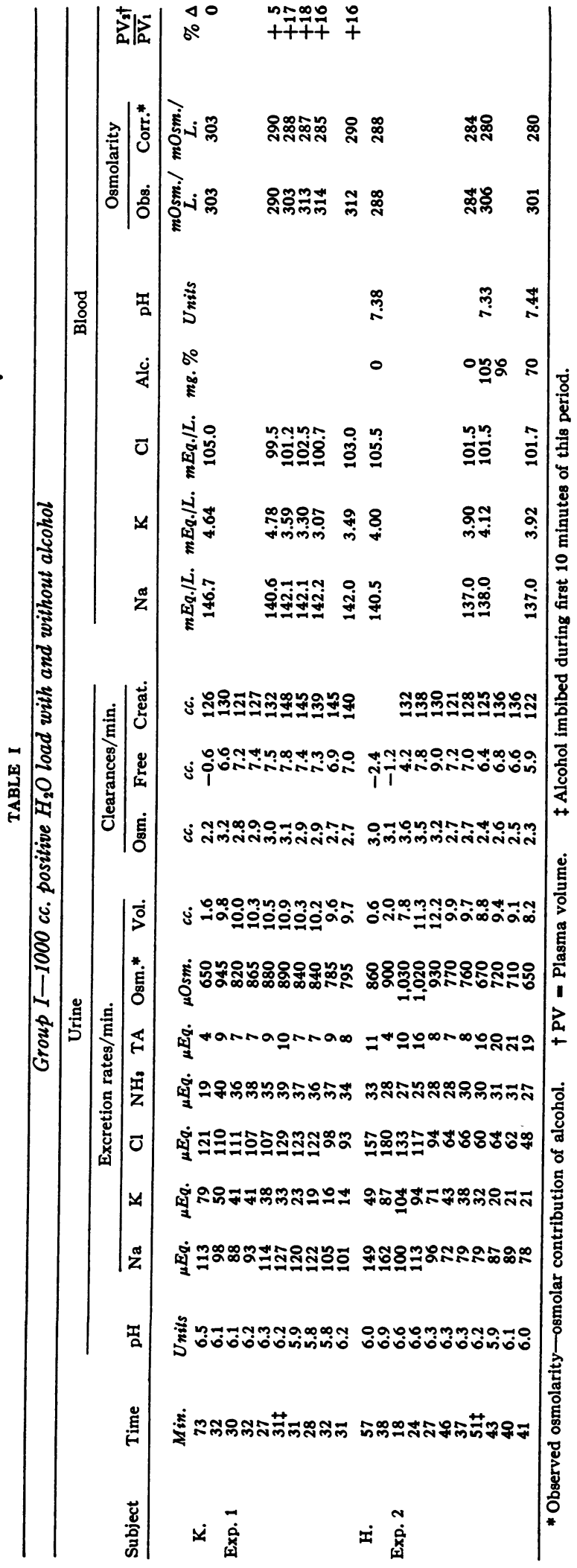

of $\mathrm{Na}$ and $\mathrm{Cl}$ did not decrease after alcohol ingestion and although the urine became more acid, excretion of ammonium was not enhanced. These results contrast sharply with the findings when alcohol is administered to subjects with low or moderate urinary flows (1).

Group IIa. Effect of the simultaneous administration of alcohol and hypertonic saline to water-loaded subjects (Table IIA, Figure $1 A$ and $1 B$ )

Positive water balances were achieved in four experiments in a manner similar to that described for Group I. In two control tests (No. 1 and No. 2 Table IIA) 500 cc. of hypertonic saline ( 5 to 6 per cent) was infused without alcohol. In two further experiments (No. 3 and No. 4, Table IIA), alcohol was imbibed simultaneously with the beginning of the hypertonic infusion.

The administration of hypertonic saline without alcohol, at the height of a water diuresis, was followed by a prompt decrease in urine flow and free water clearance (Figure 1A). In contrast, the subjects receiving alcohol not only failed to show an antidiuresis, but actually increased their flow of urine above the levels reached during maximal water diuresis (Figure 1B). Free water clearance $\left(\mathrm{C}_{\mathrm{H}_{2}} \mathrm{O}\right)$ increased in spite of a 4 to 5 per cent rise in the osmolarity of the serum. It is apparent that alcohol effectively blocked the antidiuretic response to hypertonic saline.

Group IIb. Effect of alcohol on the antidiuresis following hypertonic saline in subjects with low urine flows (Table IIB, Figure 2)

In two subjects, $300 \mathrm{cc}$. of 5 to 6 per cent saline were infused intravenously after a suitable control period. Approximately 30 minutes after starting the infusion alcohol was imbibed.

In neither subject did a water diuresis occur after alcohol. Prior administration of hypertonic saline, with a consequent increase in the effective osmotic pressure of extracellular fluid, presumably induced the release of increased amounts of ADH from the posterior pituitary (4). Since alcohol affects neither exogenous ADH nor the ability of the tubules to respond to this hormone (5) an excess of circulation ADH probably masked the inhibitory effect of alcohol upon the supraopticohypophyseal system in these experiments.

\section{Group III. Effect of alcohol on the antidiuresis of venous congestion (Table III, Figure 3)}

The effect of alcohol on the antidiuresis produced by venous congestion of the limbs was tested in three subjects in whom sphygmomanometer cuffs were inflated about the thighs to a pressure of 70 to $80 \mathrm{~mm}$. Hg. (In all, a positive water load of $500 \mathrm{cc}$. was established and maintained throughout the experiment.) In two studies (No. 1 and No. 2, Table III) a control period of venous congestion for $\mathbf{3 0}$ minutes, instituted after maximal urine flow had been attained, produced a prompt fall in urine flow, $\mathrm{C}_{\mathrm{H}_{2} \mathrm{O}}$, and $\mathrm{C}_{\mathrm{osm}}$, as well as in the rates of excretion of sodium, potassium, chloride, and creatinine. These 


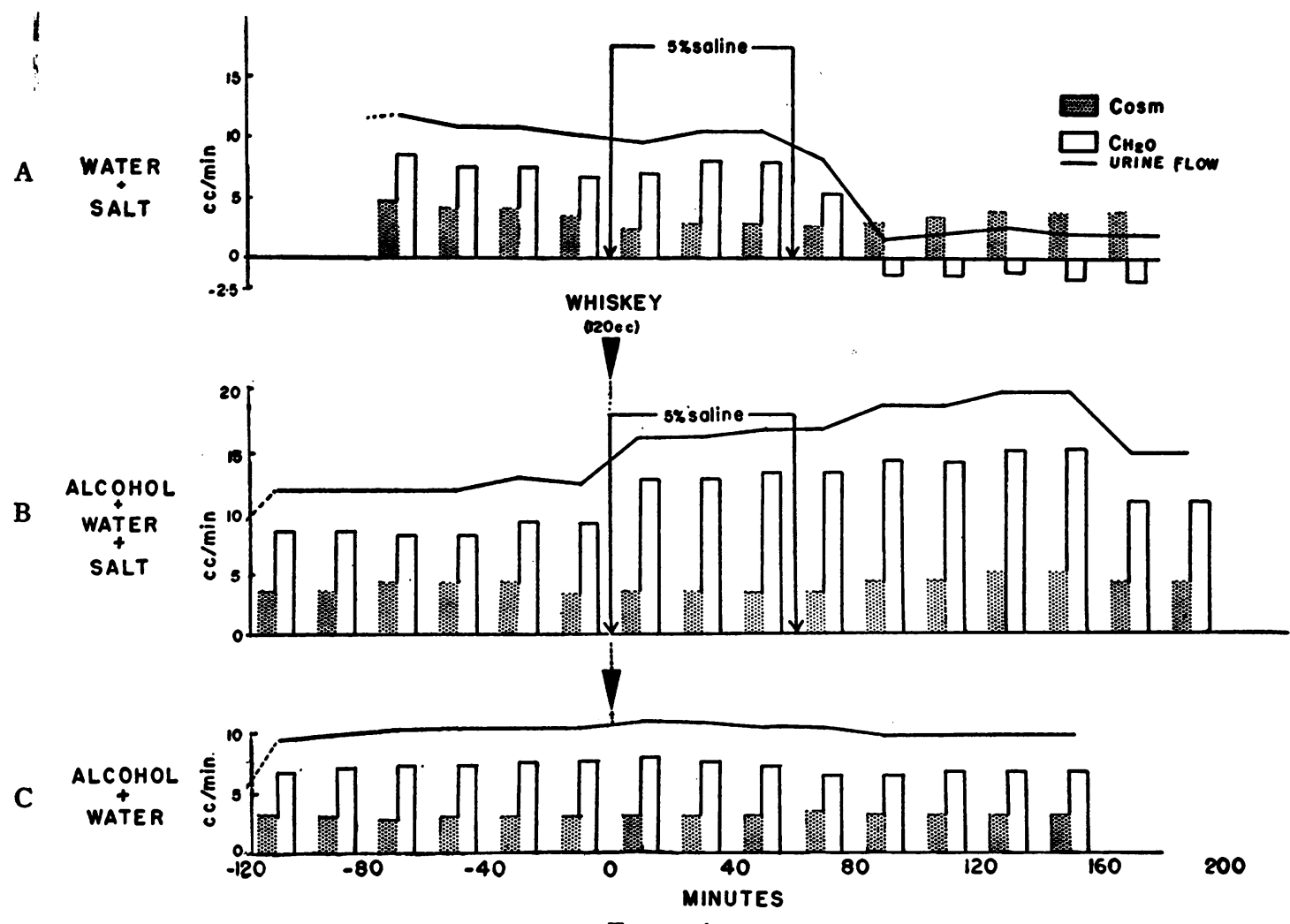

FIGURE 1

Alcohol produced no increase in an established water diuresis (Figure 1C). In contrast, when alcohol was given with an intravenous load of hypertonic saline, urine flow and $\mathrm{C}_{\mathrm{H}_{2} \mathrm{O}}$ increased (Figure 1B), and the characteristic antidiuretic effect of hypertonic saline (Figure 1A) was blocked.

A ALCOHOL

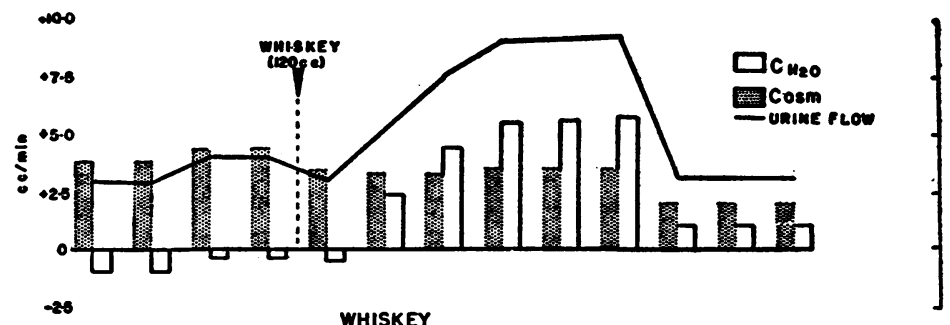

B

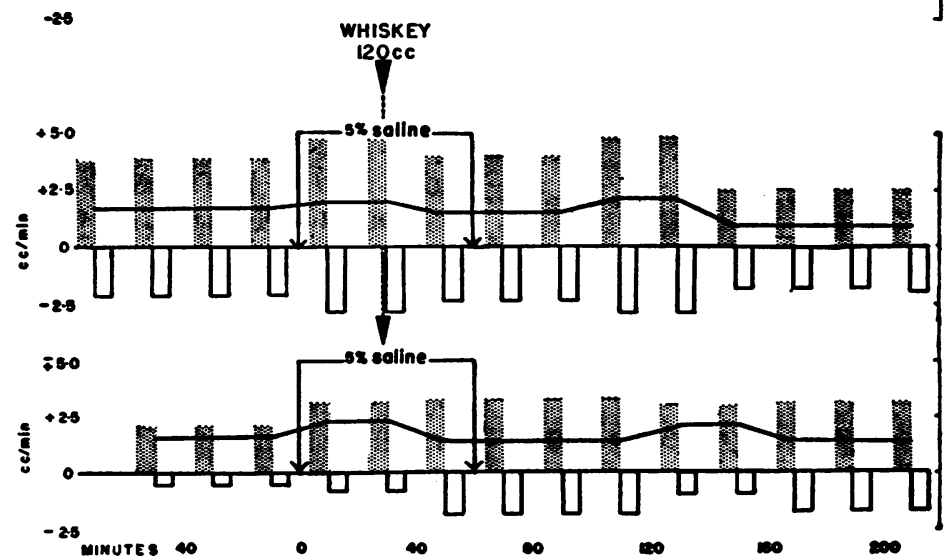

Figure 2

Prior administration of hypertonic saline (Figures 2B and 2C) blocked the characteristic diuresis following alcohol (Figure 2A). 
II. ETHANOL INHIBITION OF THE NEUROHYPOPHYSIS

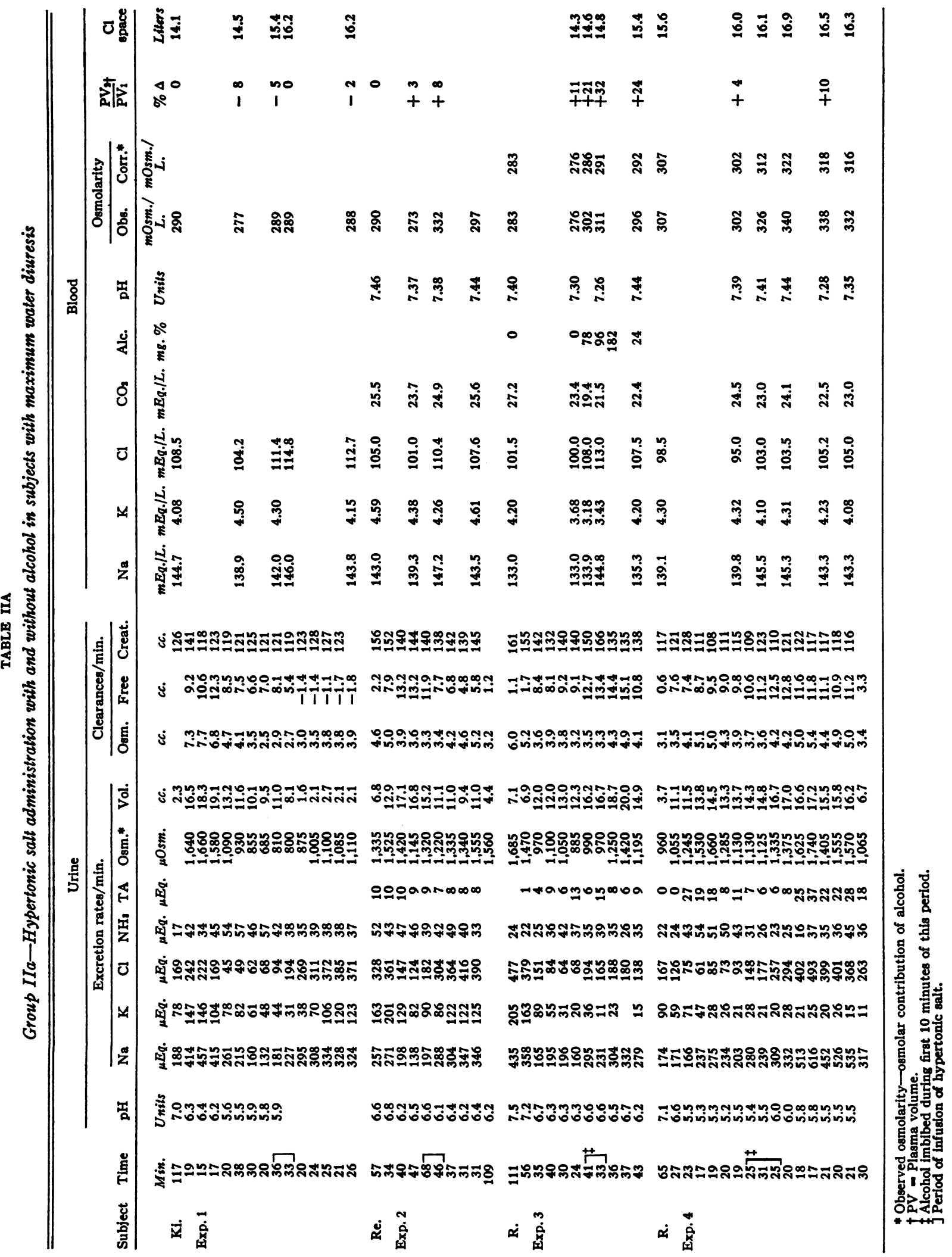


functions returned to or toward control levels after the congestion was released. After a suitable period of recovery, during which the urine flow stabilized, alcohol was administered 30 minutes prior to the application of congesting cuffs for the second time, this time for $60 \mathrm{~min}$ utes. Despite a more prolonged period of venous congestion, only slight falls in urine flow and free water clearance were produced, although the decrease in solute excretion and $C_{o s m}$ was comparable to that during the control period of cuffing. Under these circumstances, therefore, prior ingestion of alcohol minimized the antidiuretic effect of venous congestion (Figure 3A).

In a third subject (No. 3, Table III), alcohol was imbibed 100 minutes after the cuffs had been inflated. Urine flow and $\mathrm{CH}_{2} \mathrm{O}$, which had diminished after the cuffs had been applied, did not increase after alcohol was administered, and started to rise only after the cuffs were released (Figure 3B).

\section{DISCUSSION}

In the present study, alcohol prevented or minimized the fall of urine flow and free water clearance $\left(\mathrm{CH}_{2} \mathrm{O}\right)$ that characteristically follows the administration of hypertonic solutions of sodium chloride or venous congestion of the extremities. Alcohol will also prevent the antidiuresis of dehydration (6) or the administration of acetylcholine (7) and nicotine (6), and it has no effect on urine flow when it is given at the height of water diuresis or to dogs with diabetes insipidus (7). These observations constitute overwhelming evidence that it has an inhibitory action on the supraopticohypophyseal system.

The antidiuresis that regularly follows venous congestion of the lower extremities or stationary standing has been ascribed in part to increased activity of the neurohypophysis as a result of diminished effective blood volume $(8,9)$. Facts in favor of this interpretation are: 1) a diminished or absent response in subjects with diabetes insipidus or in hydropenic subjects with maximal $\mathrm{ADH}$ activity who are undergoing a mannitol diuresis $(10)$; 2) a fall in urine flow out of proportion to the changes in electrolyte excretion and glomerular filtration $(8,9) ; 3)$ the appearance of an antidiuretic substance in the blood of normal subjects after circulatory collapse induced by motionless standing (11). The ability of alcohol to inhibit the antidiuresis of venous congestion lends added weight to the concept that changes in urine flow following alterations in the volume and distribution of body fluids are to an important degree 
II. ETHANOL INHIBITION OF THE NEUROHYPOPHYSIS

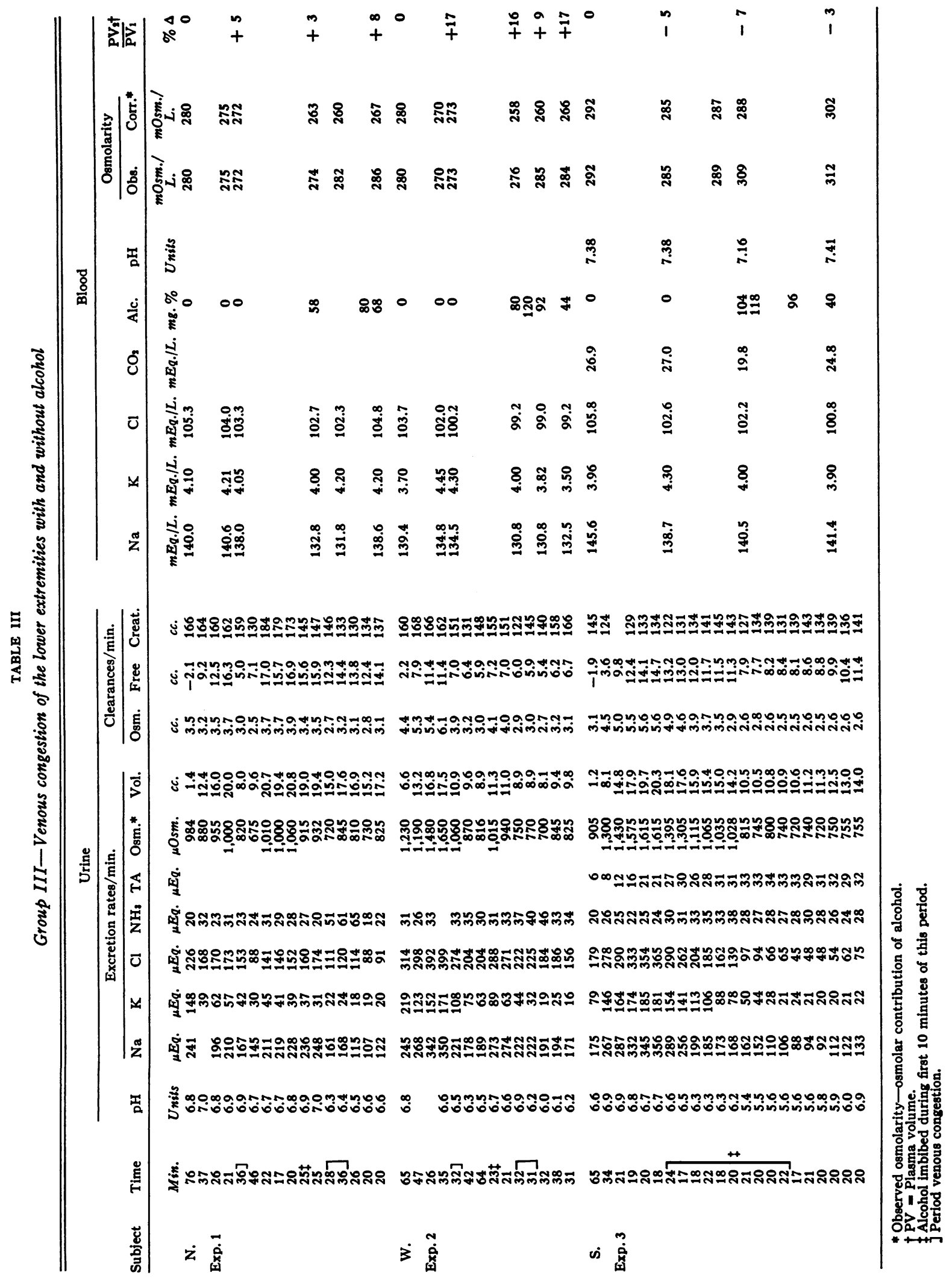




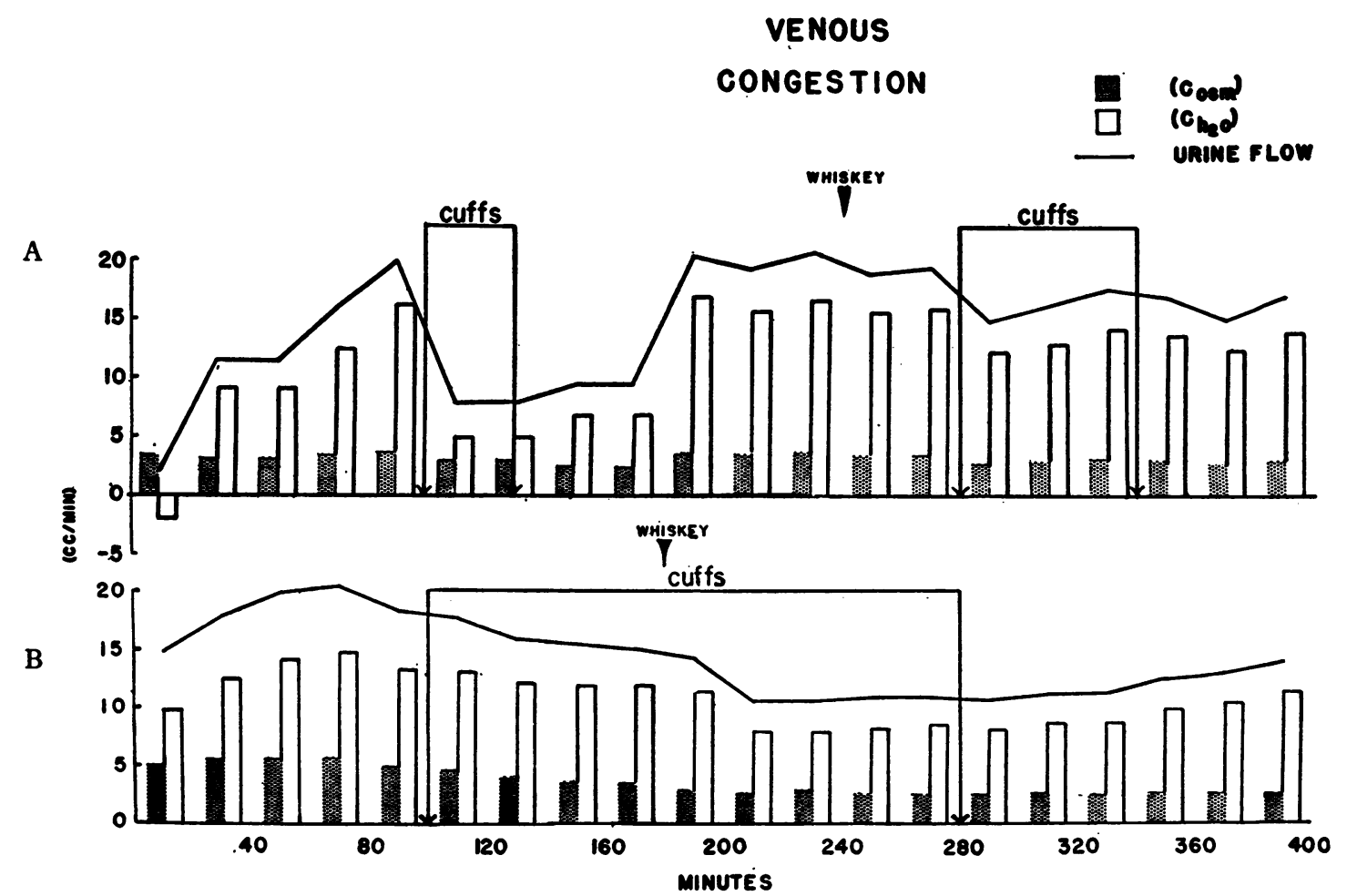

FIgURe 3

Alcohol minimized the antidiuretic effect of venous congestion when given prior to the latter (Figure $3 \mathrm{~A}$ ). In contrast, alcohol had little effect when given during the period of venous congestion (Figure $3 \mathrm{~B})$.

secondary to variations in the activity of the neurohypophysis. ${ }^{\circ}$

Alcohol had little effect on urine flow and free water clearance in those experiments in which it was given after an infusion of hypertonic saline or venous congestion had been initiated. Once the neurohypophysis has been stimulated the resultant excess of circulating antidiuretic hormones might, until it is inactivated or destroyed, mask the temporary inhibition of the posterior pituitary by alcohol. These experiments suggest that alcohol diuresis may be blocked by a prior rise in circulating endogenous $\mathrm{ADH}$ as well as by the administration of exogenous Pitressin ${ }^{\circledR}(5,6)$.

In the experiments of Group I, when the release of ADH was presumably completely inhibited by a positive water load in the semi-recumbent position, administration of alcohol caused no further rise in urine flow and free water clearance.

- In a study published since completion of this paper Newman (12) demonstrated that alcohol could effectively block the antidiuresis of quiet standing.
The increase in $\mathrm{CH}_{2} \mathrm{O}$ which occurred in the waterloaded subjects of Group IIb, to whom alcohol was given simultaneously with an infusion of hypertonic saline, was therefore unexpected. The situation in these experiments is probably comparable to the rapid administration of large solute loads to patients with diabetes insipidus, in whom an increased volume of isosmotic fluid is suddenly delivered to a distal tubular segment in which water reabsorption is blocked but where further reabsorption of solute does occur. In this case an increase in the calculated value of free water clearance $\left(\mathrm{C}_{\mathrm{H}_{2}} \mathrm{O}\right)$ might be produced, not by diminished reabsorption of water in the distal tubule (Smith, 13), but by an increased distal reabsorption of solute. An increase in $\mathrm{CH}_{2} \mathrm{O}$ during mannitol or solute diuresis in subjects with diabetes insipidus can in fact be demonstrated by recalculating the data of Brodsky and Rapoport (14). Similar increases in $\mathrm{C}_{\mathrm{H}_{2} \mathrm{O}} \mathrm{O} \mathrm{C}_{\mathrm{osm}}$, and urine flow were shown by Welt, Young, Thorup, and Burnett (15) to follow the adminis- 
tration of a carbonic anhydrase inhibitor to waterloaded subjects who were in a state of "physiological diabetes insipidus." Although tubular secretion of water (14) could explain such changes, there seems little reason to invoke such a concept.

A relative or absolute increase in antidiuretic hormone has been implicated in the abnormal water metabolism of such clinical states as hyponatremia, cirrhosis of the liver, congestive heart failure, adrenal insufficiency, and panhypopituitarism. The results of the present and previous studies $(1,5)$ suggest that the effects of alcohol in states of abnormal water metabolism might be of value in interpreting their pathophysiology. Such investigations are now in progress.

\section{SUMMARY}

1. Alcohol had no effect upon urine flow or solute excretion when given at the height of a water diuresis.

2. Alcohol blocked the antidiuretic response to hypertonic saline when both were simultaneously administered to water-loaded subjects.

3. Alcohol minimized the antidiuretic effect of venous congestion of the legs in water-loaded subjects, when imbibed before the legs were congested.

4. The characteristic diuretic response to alcohol was blocked by prior infusion of hypertonic saline or cuff congestion of the limbs.

5. When administered prior to the stimulus, alcohol will effectively block stimulation of the release of $\mathrm{ADH}$.

\section{ACKNOWLEDGMENT}

The authors wish to thank Dr. John P. Peters for his advice and criticism and Drs. D. Lester and L. J. Greenberg of the Department of Applied Physiology, Yale University for their suggestions and assistance in setting up the technique for alcohol determination in the blood. The technical assistance of Mrs. M. Browning and Mrs. M. Kompare is gratefully acknowledged.

\section{REFERENCES}

1. Rubini, M. E., Kleeman, C. R., and Lamdin, E., Studies on alcohol diuresis. I. The effect of ethyl alcohol ingestion on water, electrolyte and acidbase metabolism. J. Clin. Invest., 1955, 34, 439.

2. Stanbury, S. W., and Thomson, A. E., Diurnal variation in electrolyte excretion. Clin. Sc., 1951, 10, 267.

3. Elkinton, J. R., and Taffel, M., Prolonged water deprivation in the dog. J. Clin. Invest., 1942, 21, 787.

4. Verney, E. B., The antidiuretic hormone and the factors which determine its release. Proc. Roy. Soc., London, s. B., 1947, 135, 25.

5. Strauss, M. B., Rosenbaum, J. D., and Nelson, W. P., III, The effect of alcohol on the renal excretion of water and electrolyte. J. Clin. Invest., 1950, 29, 1053.

6. Eggleton, M. G., The diuretic action of alcohol in man. J. Physiol., 1942, 101, 172.

7. van Dyke, H. B., and Ames, R. G., Alcohol diuresis. Acta Endocrinol., 1951, 7, 110.

8. Wilkins, R. W., Tinsley, C. M., Culbertson, J. W., Burrows, B. A., Judson, W. E., and Burnett, C. $H$., The effects of venous congestion of the limbs upon renal clearances and the excretion of water and salt. I. Studies in normal subjects and in hypertensive patients before and after splanchnicectomy. J. Clin. Invest., 1953, 32, 1101.

9. Fitzhugh, F. W., Jr., McWhorter, R. L., Jr., Estes, E. H., Jr., Warren, J. V., and Merrill, A. J., The effect of application of tourniquets to the legs on cardiac output and renal function in normal human subjects. J. Clin. Invest., 1953, 32, 1163.

10. Judson, W. E., Epstein, F. H., Tinsley, C. M., Burrows, B. A., and Wilkins, R. W., The hemodynamics and renal functional effects of venous congestion of the limbs in patients with diabetes insipidus. J. Clin. Invest., 1950, 29, 826.

11. Brun, C., Knudsen, E. O. E., and Raaschou, F., On the cause of post-syncopal oliguria. Acta med. Scandinav., 1945, 122, 486.

12. Newman, E. V., Metabolic adjustments to normal and disturbed circulation in man. New England $J$. Med., 1954, 250, 347.

13. Smith, H. W., The Kidney, Structure and Function in Health and Disease. New York, Oxford University Press, 1951.

14. Brodsky, W. A., and Rapoport, S., The mechanism of polyuria of diabetes insipidus in man. The effect of osmotic loading. J. Clin. Invest., 1951, 30, 282.

15. Welt, L. G., Young, D. T., Thorup, O. A., Jr., and Burnett, C. H., Renal tubular phenomena under the influence of a carbonic anhydrase inhibitor. Am. J. Med., 1954, 16, 612. 